\title{
Study of clinical risk factors for vitreous haemorrhage
}

\author{
Raghuwanshi S ${ }^{1}$, Raghuwanshi S.K. ${ }^{2}$ \\ ${ }^{1}$ Dr. Sapna Raghuwanshi, Senior Resident, Ophthalmology, ${ }^{2}$ Dr. Shivkumar Raghuwanshi, Associate Professor, ENT. \\ Both are affiliated with L N Medical College Bhopal, MP, India.
}

\begin{abstract}
Address for Correspondence: Dr. Sapna Raghuwanshi, Senior Resident, Ophthalmology, E-mail:
\end{abstract} drsapnaraghuwanshi@gmail.com

\begin{abstract}
Background: Vitreous haemorrhage is one of the common causes of visual loss and it is due to number of risk factors. This study aims to establish an early etiology of vitreous haemorrhage in our environment which provides proper treatment to help in early absorption and prevention of complications so as to avoid irreversible damage to sight. Methods: A 20 months retrospective review of medical records of patients who admitted in the department of ophthalmology, Gandhi Medical College and associated Hamidia Hospital, Bhopal with vitreous haemorrhage between from April 2010 to December 2011. Demographic data, etiological factors of vitreous haemorrhage and involved eye were amongst the information culled from the records and analysed. Results: Seventy five patients were seen over the period under review out of which $78 \%$ they were males. The age range was $16-45$ years. Vascular disorders (48\%) and trauma accounted for $29.33 \%$ of all the causes of vitreous haemorrhage. Conclusion: vascular disorder is a significant cause of vitreous haemorrhage in our environment affecting the all age group and while considering individual aetiological factors the ocular trauma showed highest incidence. The poor presenting visual acuity reflects the severity of causes of vitreous haemorrhage. Awareness needs to be increased to assess the causes and risk factors of vitreous haemorrhage.
\end{abstract}

Keywords: Vitreous haemorrhage, Etiology, Vision loss.

\section{Introduction}

Vitreous haemorrhage is one of the commonest causes for loss of vision. Vitreous haemorrhage is defined as the presence of extravasated blood within the space outlined by the internal limiting membrane of retina posteriorly and laterally, the non-pigmented epithelium of ciliary body antero-laterally and lens zonules and posterior lens capsule anteriorly [1].

This condition may result directly from retinal tears or neovascularization of the retina or it may be related to bleeding from pre-existing blood vessels in these structures. The vitreous is avascular and inelastic. Pathological mechanisms of vitreous haemorrhage can include haemorrhage from diseased retina, traumatic insult, and/or spread of haemorrhage into the retina and vitreous from any other intraocular sources. Sometimes, it may be reasonable to consider extra ocular etiologies

Manuscript received: $23^{\text {rd }}$ Jan 2016

Reviewed: $02^{\text {nd }} \mathrm{Feb} 2016$

Author Corrected: $12^{\text {th }}$ Feb 2016

Accepted for Publication: $22^{\text {nd }}$ Feb 2016 such as blood dyscrasias or leukaemia. Usually, coagulation disorders or anticoagulant therapy does not cause vitreous haemorrhage; however, bleeding from abnormal new vessels or rupture of normal retinal vessels from direct or indirect trauma frequently is associated with vitreous haemorrhage. Bleeding from neovascular and fragile vessels in proliferative diabetic retinopathy, proliferative sickle cell retinopathy, ischemic retinopathy secondary to retinal vein occlusion, and retinopathy of prematurity are among the most common pathological causes of vitreous haemorrhage. Age, race and sex of vitreous haemorrhage have also been found to correspond with the underlying etiology. Patients usually present with a diminution of vision which could be sudden or progressive. Visual acuity depends upon the degree of haemorrhage, dense haemorrhage can reduce vision to 'light perception' in the absence of trauma there is usually no associated pain with $\mathrm{VH}$. Ocular ultrasound scan is most useful investigation in giving information 
regarding the state of the retina when fundoscopy cannot be carried out. Treatment is usually targeted at the underlying cause. Pars plana vitrectomy may be carried out where indicated [1]. This study was planned to analyze vitreous haemorrhage in a retrospective series of admitted cases in the department of ophthalmology, Hamidia hospital and Gandhi Medical
College, Bhopal to establish an early etiology of vitreous haemorrhage in our environment which provides proper treatment to help in early absorption and prevention of complications so as to avoid irreversible damage to sight. This would further help in postulating strategy for its prevention and in decreasing incidence of blindness in our country.

\section{Materials and Methods}

This study is a retrospective non comparative study of 75 patients who admitted patients in the department of ophthalmology, Gandhi Medical College and associated Hamidia Hospital, Bhopal. Data was analysed from the medical records of patients who admitted with vitreous haemorrhage between from April 2010 -to-December 2011. Analysis of different Parameters including the patients' demographic data (age, sex), aetiological factors and involved eye were done.

\section{Result}

Seventy five patients were included in the study.

Demographic And Baseline Characteristics- In the present study the incidence of vitreous haemorrhage was greatest between 16-45 years (68\%). Male preponderance was observed in the present series, $78 \%$ patients were male. Average male: female ratio is 1:0.41 (Table 1). $61.33 \%$ patients belong to lower socio-economic group, $36.0 \%$ to middle and $2.67 \%$ to upper socio-economic group according to kuppuswamy' socioeconomic classification ( Table 2). $94.67 \%$ cases show unilateral involvement (Table 3).

Table 1: Table showing age and sex distribution of cases of vitreous haemorrhage

\begin{tabular}{|c|c|c|c|c|c|}
\hline \multirow[t]{2}{*}{ S.No } & \multirow{2}{*}{$\begin{array}{l}\text { Age group in } \\
\text { years }\end{array}$} & \multicolumn{2}{|l|}{ Sex } & \multirow[t]{2}{*}{ Total } & \multirow{2}{*}{$\begin{array}{l}\text { Male/female } \\
\text { ratio }\end{array}$} \\
\hline & & Male & Female & & \\
\hline 1 & $0-15$ & 2 & 3 & 5 & $1: 15$ \\
\hline 2 & $16-30$ & 27 & 6 & 33 & $1: 0.22$ \\
\hline 3 & $31-45$ & 13 & 5 & 18 & $1: 0.38$ \\
\hline 4 & $46-60$ & 8 & 7 & 15 & $1: 0.87$ \\
\hline 5 & Above 60 & 3 & 1 & 4 & $1: 0.33$ \\
\hline Total & & 53 & 22 & 75 & 1:0.41 \\
\hline
\end{tabular}

Table 2: Table showing distribution of cases of vitreous haemorrhage in different socio-economic groups

\begin{tabular}{|l|l|l|l|}
\hline Sr. No & Socio-economic group & No of cases & Percentage \\
\hline 1 & Lower & 46 & $61.33 \%$ \\
\hline 2 & Middle & 27 & $36.0 \%$ \\
\hline 3 & Upper & 2 & $2.67 \%$ \\
\hline
\end{tabular}

Table 3: Table showing distribution of cases of vitreous haemorrhage as per involvement of eye

\begin{tabular}{|l|l|l|l|}
\hline Sr. No & Eye involved & No of cases & Percentage \\
\hline 1 & Unilateral & 71 & $94.67 \%$ \\
\hline I & Right eye & 36 & \\
\hline Ii & Left eye & 35 & \\
\hline 2 & Bilateral & 4 & $5.33 \%$ \\
\hline
\end{tabular}


Etiology- Maximum cases $(48.0 \%)$ belong to the group of vascular disorders ( $48 \%$ ) which included Perivasculitis (26.66\%), diabetes mellitus (17.33\%)and hypertension(4.0\%). Next commonest cause was ocular trauma(29.33\%) other causes was retinal detachment $(5.33 \%)$ uveitis $(5.33 \%)$ blood dyscrasis $(4 \%)$ and papilloedema $(2,66 \%)$ in 4 cases $(5.33 \%)$ the diagnosis could not be established(Table 4$)$.

Table 4: Table showing Etiological distribution of cases of vitreous hemorrhage

\begin{tabular}{|l|l|l|l|}
\hline Sr. No & Etiology & No of cases & Percentage \\
\hline 1 & Vascular disorders & $(36)$ & $48 \%$ \\
\hline I & Perivasculitis & 20 & $26.66 \%$ \\
\hline Ii & Diabetes mellitus & 13 & $17.33 \%$ \\
\hline Iii & Hypertension & 3 & $4.0 \%$ \\
\hline 2 & Ocular trauma & 22 & $29.33 \%$ \\
\hline 3 & Retinal detachment & 4 & $5.33 \%$ \\
\hline 4 & Uveitis & 4 & $5.33 \%$ \\
\hline 5 & Blood dyscrasias & 3 & $4.0 \%$ \\
\hline 6 & Papilloedema & 2 & $2.66 \%$ \\
\hline 7 & Uncertain & 4 & $5.33 \%$ \\
\hline
\end{tabular}

Correlation Of Etiology With Age And Sex- Under the age group of 45 ocular traumas (25.33\%), Perivasculitis (24\%) were the common aetiological factors. while diabetes mellitus (13.33\%) was the commonest factor above 45 yrs (Table $5)$.

Table 5: Table showing Etiological distribution of cases of vitreous hemorrhage in different age groups

\begin{tabular}{|l|l|l|l|l|l|l|}
\hline Sr. No & Etiology & $\mathbf{0 - 1 5}$ & $\mathbf{1 6 - 3 0}$ & $\mathbf{3 1 - 4 5}$ & $\mathbf{4 6 - 6 0}$ & Above 60 \\
\hline 1 & Vascular disorders & & & & & \\
\hline I & Perivasculitis & - & 12 & 6 & 2 & - \\
\hline Ii & Diabetes mellitus & - & 1 & 2 & 7 & 3 \\
\hline Iii & Hypertension & - & 1 & 1 & 1 & - \\
\hline 2 & Ocular trauma & 3 & 10 & 6 & 2 & 1 \\
\hline 3 & $\begin{array}{l}\text { Retinal } \\
\text { detachment }\end{array}$ & - & 2 & 1 & 1 & - \\
\hline
\end{tabular}

Table 6: Table showing Distribution of cases of vitreous hemorrhage in different etiological groups

\begin{tabular}{|l|l|l|l|}
\hline \multirow{2}{*}{ Sr. No } & Etilogy & No of cases \\
\cline { 3 - 4 } & & Male & Female \\
\hline 1 & Vascular disorders & $(28)$ & $(8)$ \\
\hline I & Perivasculitis & 20 & 0 \\
\hline Ii & Diabetes mellitus & 7 & 6 \\
\hline Iii & Hypertension & 1 & 2 \\
\hline 2 & Ocular trauma & 15 & 7 \\
\hline 3 & Retinal detachment & 2 & 2 \\
\hline 4 & Uveitis & 2 & 2 \\
\hline 5 & Blood dyscrasias & 1 & 2 \\
\hline 6 & Papilloedema & 2 & 0 \\
\hline 7 & Uncertain & 3 & 1 \\
\hline
\end{tabular}

Male preponderance was observed in vascular disorders and ocular trauma. The male to female ratio was 3.5:1 in vascular disorders and2.1:1 in ocular trauma. In Perivasculitis all patients were males. No significant difference was observed in other aetiological group (Table 6). 


\section{Discussion}

The prevalence of vitreous haemorrhage related to the frequency of the causative disease and this depends on the study population, mean age of patients and the geographical region where the study is conducted.

The incidence of vitreous haemorrhage was greatest between 15-45 years (68\%). Male preponderance was observed in the present series, $78 \%$ patients were male. These observations are similar to those made Lean and Gregor [2]. This higher incidence can be attributed to the more implication of young males in ocular trauma and Perivasculitis, which formed the major aetiological groups in this study.

A higher incidence of vitreous haemorrhage was observed in lower socio-economic group comprising mainly of factory workers, farmers and labourers. This was observed specially on Perivasculitis and ocular trauma. This can be explained by high risk of exposure to trauma, under nutrition and poor environmental hygiene.

Etiology- Results show that vascular disorders (48\%) and ocular trauma (29.33\%) were the leading causes. While considering individual aetiological factors the ocular trauma showed highest incidence. Perivasculitis was the commonest cause among vascular disorders, followed by diabetes and hypertension. Other less common causes included uveitis, retinal department, blood dyscrasias and papilloedema.

These figures have been compared with observations made by other authors in the Table 7.

Table 7: Table showing the result of comparison made by others authors

\begin{tabular}{|l|l|l|l|l|l|}
\hline $\begin{array}{l}\text { S. } \\
\text { No. }\end{array}$ & Etiology & $\begin{array}{l}\text { Morse et al. } \\
\mathbf{1 9 7 4}(\boldsymbol{\%})\end{array}$ & $\begin{array}{l}\text { Lean \& Gregor } \\
\mathbf{1 9 8 0}(\boldsymbol{\%})\end{array}$ & $\begin{array}{l}\text { Jampol LM et al. } \\
\mathbf{1 9 9 4}(\boldsymbol{\%})\end{array}$ & $\begin{array}{l}\text { Present Study } \\
(\boldsymbol{\%})\end{array}$ \\
\hline 1 & Perivasculitis & - & - & - & 26.6 \\
\hline 2 & D.M. & 84.0 & 7.0 & 19.1 & 17.37 \\
\hline 3 & Hypertension & 2.0 & 1.0 & - & 4.0 \\
\hline 4 & Trauma & - & 12.0 & 18.8 & 29.3 \\
\hline 5 & Uveitis & 1.0 & - & - & 5.33 \\
\hline 6 & R.D. & 28.0 & 44.0 & 7.10 & 5.33 \\
\hline 7 & Blood Dyscrasias & 1.0 & 1.0 & 0.2 & 4.0 \\
\hline 8 & Papilloedema & - & - & - & 2.6 \\
\hline 9 & Undiagnosed & 3.0 & 4.0 & 7.6 & 5.3 \\
\hline
\end{tabular}

Morse et al did not include traumatic vitreous haemorrhage in his study [3]. Morse et al and Lean and Gregor, jampol LM et al not describe Perivasculitis as a cause of vitreous haemorrhage $[4,2]$.

Vascular Disorders- In the present series, the incidence of Perivasculitis was higher. These findings are not consistent with observation of Morse et al (1974) and Lean and Gregor (1980), Kumar D et al 1995 [3, 2, 5]. This difference can be attributed to higher incidence of infectious diseases i.e. tuberculosis and syphilis in India as a result of malnutrition and poor hygienic conditions. The incidence of diabetes was $17.3 \%$ much lower than that observed by Morse, Dana et al but higher than incidence in Lean and Gregor series [ 3,6,2]. This discrepancy is due to different mode of selection of cases. Hypertension was reported in $4.0 \%$ cases of present series. The findings are consistent with that of other authors [3, 2].

Ocular Trauma-Ocular Trauma was found to be responsible for $29.33 \%$ cases of vitreous haemorrhage, out of which $68.0 \%$ were caused by blunt trauma. While considering individual aetiological factors the ocular trauma showed highest incidence. Rotimi et al also reported trauma to be the commonest cause of vitreous haemorrhage in Western Nigeria this was followed by proliferative sickle cell retinopathy in their series [7]. Higher incidence than Jampol LM et al can be explained by the fact that cases of old injuries are also included in the present series [4].

Retinal Detachment-In 5.33\% cases of the present series the cause of haemorrhage was found to be the retinal detachment with or without retinal tear. This figure was similarly to observations of Jampol LM et al (1995) [4]. 
Other Causes-The incidence in uveitis, papilloedema and blood dyscrasias, PVD are roughly similar to observations made by others $[1,8,9]$. The other rare causes include Terson's syndrome and Valsalva retinopathy [10]

Correlation with age and sex-In the present study ocular trauma and Perivasculitis were the leading aetiological factors under 45 year; age, whereas diabetes mellitus predominated above 45 years. Male preponderance was observed among the cases of Perivasculitis and trauma, whereas for other disease the ratio was almost 1:1.

Ocular Preponderance-In the present series unilateral involvement was seen in $94.6 \%$ cases. Bilateral involvement was seen only in 5.33\% cases which were of diabetes and Perivasculitis, an observation similar to Dana et al. (1993) [6]. Management of Vitreous haemorrhage involves managing the underlying cause.

\section{Conclusion}

In all patients presenting with blurring of vision, indirect ophthalmoscopy should be carried out to detect peripheral lesion and vitreous haemorrhage thus ensuring early treatment and better prognosis.

A detailed history and thorough examination including ophthalmoscopy of the fellow eye helped in correlating aetiological diagnosis of vitreous haemorrhage.

\section{Funding: Nil}

Conflict of interest: None.

Permission of IRB: Yes

\section{Reference}

1. Spraul CW, Grossniklaus HE. Vitreous Hemorrhage. Surv Ophthalmol. 1997 Jul-Aug;42(1):3-39.

2. Lean JS, Gregor Z. The acute vitreous haemorrhage. Br J Ophthalmol. 1980 Jul;64(7):469-71.

3. Morse PH, Aminlari A, Scheie HG. Spontaneous vitreous hemorrhage. Arch Ophthalmol. 1974 Oct;92(4):297-8.

4. Jampol LM, Ebroon DA, Goldbaum MH. Peripheral proliferative retinopathies: an update on angiogenesis, etiologies and management. Surv Ophthalmol. 1994 May-Jun;38(6):519-40.
5. Kumar D, Saxena RC, Saxena S. Vitreous haemorrhage in Eales' disease. Afro-Asian J Ophthalmol 1995; 13: 19-22.

6. Dana MR, Werner MS, Viana MA, Shapiro MJ. Spontaneous and traumatic vitreous hemorrhage. Ophthalmology. 1993 Sep;100(9):1377-83.

7. Rotimi-Samuel A, Aribaba OT, Mbadugha CA, Ilo AO, Onakoya AO, , Akinsola FB, Adefule-Ositelu AO . Etiology of Vitreous Haemorrhage in Guinness Eye Centre, Lagos University Teaching Hospital over a Two Year Period (June 2007-May 2009).Nig Q J Hosp. Med 2010; 20(4): 162-164.

8. Chang TS, Aylward GW, Davis JL, Mieler WF, Oliver GL, Maberley AL, Gass JD. Idiopathic retinal vasculitis, aneurysms, and neuro-retinitis. Retinal Vasculitis Study. Ophthalmology. 1995 Jul;102(7):1089-97.

9. Sarrafizadeh R, Hassan TS, Ruby AJ, Williams GA, Garretson BR, Capone A Jr, Trese MT, Margherio RR. Incidence of retinal detachment and visual outcome in eyes presenting with posterior vitreous separation and dense fundus-obscuring vitreous haemorrhage. Ophthalmology 2001; 108 (12): 2273-78.

10. Ogawa T, Kitaoka T, Dake Y, Amemiya T. Terson syndrome: a case report suggesting the mechanism of vitreous hemorrhage. Ophthalmology. 2001 Sep;108(9):1654-6.

\section{How to cite this article?}

Raghuwanshi S , Raghuwanshi S.K. Study of clinical risk factors for vitreous haemorrhage. Int J Med Res Rev 2016;4(2):233-237. doi: 10.17511/ijmrr.2016.i02.018. 